\title{
The Influence of Oral Environment on the Optical Properties of Heat- pressed Ceramics
}

\begin{abstract}
ROXANA-DIANA VASILIU1*, SORIN POROJAN², LILIANA POROJ AN ${ }^{1}$
IV.ictor Babes University of Medicine and Pharmacy Timisoara, Faculty of Dentistry, Department of Prostheses Technology, Specialization Dental Technology, 9 Revolutiei1989 Blvd, Timiooara,Romania

${ }^{2}$ V.ictor Babes University of Medicine and Pharmacy Timisoara, Faculty of Dentistry, Department of Oral Rehabilitation, Specialization Dental Technology, 9 Revolutiei 1989 Blvd, Timisoara, Romania

The interest in aesthetics of dental materials is becoming greater with time and dental ceramics have proven excellentaesthetic properties. The study investigated how does the oral environment and the different surface finishing affect the optical properties and roughness of two types of ceramic, obtained using the heat-pressed method. Results showed that immersion has some influence on the optical and roughness of the two types of ceramics, but the major influence is made by the surface finishing and the type of ceramic. Lithium disilicate ceramic proved to have better optical properties compared to feldspathic ceramic. Roughness values showed that the parameters( $R$ a and $R z$ ) were influenced by the surface finishing for both type of ceramics.
\end{abstract}

Keywords: heat-pressed ceramics, lithium disilicate ceramic, optical properties, roughness

The colour of the dental restorations has alw ays been a major interest in the clinical dentistry. Colour is a visual effect caused by the way light is transmitted, reflected and absorbed [1]. The colour perception is influenced by the interplay between the objects, the observers and the source of the light $[2,3]$. For many years the clinical assessment of the tooth colour was done visually by the dentist using the shade guides that matched the colour of the tooth under the same lighting conditions. A more standardized colour assessment of the tooth can be done using special devices such as colorimeters and spectrophotometers [4-6].

Spectrophotometers measure the spectral reflectance or transmittance. Transmittance is particularly important for dental restoration and it is defined as the amount of light transmitted through the material after disregarding the reflected and absorbed light [7]. The CIELAB system is frequently used to observe colour differences. This system is composed by the following coordinates L* (luminosity) , $a^{*}$ and $b^{*}$. Coordinate $L^{*}$ is attributed to lightness of the material and it represents the differences between the brightness and the darkness. The coordinate a* corresponds to differences in red- green axis and the $b^{*}$ coordinate corresponds to differences in yellow- blue axis [8) ]. In fact, lightness is considered one of the most optical properties, because the human eye is more sensitive to this property than to chroma or hue [9].

The optical behaviour of the ceramic materials is often influenced in the mouth by the value of the $\mathrm{pH}$ found. The value of $\mathrm{pH}$ can change depending on the ingested foods and beverages. The $\mathrm{pH}$ range experienced in the oral cavity can vary between 1 to 10 [10] with the highly acidic conditions associated with reflux of gastric fluids [11]. The $\mathrm{pH}$ of ingested beverages ranges from 3 to 8 [12]. Apart from the range of $\mathrm{pH}$, the oral cavity experiences a substantial temperature range from 0 to $67 \mathrm{p} \mathrm{C}$. In vitro studies have shown that the ceramic materials are susceptible to corrosion in the range of oral fluid $\mathrm{pH}$ [13].

Ceramic corrosion can affect the roughness of the materials, which can affect the survival rate of the prosthetic restoration $[14,15]$. Ceramics can be clasified by their microstructure (type of crystalline phase and glass composition), processing technique powder/liquid,pressed, or machined), and clinical application [16]. Furthermore, polishing and glazing are also applied to finalize surface texture of the ceramic material, reduce roughness and enhance light transmission influencing the optical properties.

The aim of this paper is to investigate how does the oral environment and the different surface finishing affect the optical properties of a lithium disilicate and a feldspathic ceramic.

\section{Experimental part}

Two commercially available hot pressed dental ceramic materials were used in the present study: a feldspathic glass ceramic and a lithium disilicate glass ceramic (table $1)$.

Table 1

MATERIALS USED IN THIS STUDY

\begin{tabular}{|c|c|c|}
\hline Ceramic system & Type & Composition \\
\hline $\begin{array}{l}\text { Vita PM 9 } \\
\text { Translucent }\end{array}$ & $\begin{array}{l}\text { Feldspathic } \\
\text { glass ceramic }\end{array}$ & $\begin{array}{l}\text { Feldspar } \\
\text { oxide }\end{array}$ \\
\hline $\begin{array}{l}\text { TPS e.max Press } \\
\text { Medium Translucent }\end{array}$ & $\begin{array}{l}\text { Lithium } \\
\text { disilicate glass } \\
\text { ceramic }\end{array}$ & $\begin{array}{l}57-80 \% \text { wt\% } \\
\mathrm{SiO}_{2}, 11-19 \\
\text { wt\% } \mathrm{Li}_{2} \mathrm{O} \text { and } \\
\text { other oxides } \\
\text { such as } \mathrm{K}_{2} \mathrm{O} \text {, } \\
\mathrm{MgO}, \mathrm{ZnO}, \mathrm{Al}_{2} \\
\mathrm{O}_{3}, \mathrm{P}_{2} \mathrm{O}_{3} \text {. }\end{array}$ \\
\hline
\end{tabular}

The specimens were fabricated according to the manufacturer's guidelines. Each obtained specimen was $1.5 \mathrm{~mm}$ thick and had $16 \mathrm{~mm}$ diameter. The wax patterns were invested in a phosphate- bonded investment material [Bellavest SH; BEGO GmbH \& Co. KG, Bremen, Germany]. Prefabricated ingots with medium translucency were pressed into 24 ceramic specimens using the lost- wax technique.

The pressing process was performed using a press furnace [ Multimat 2 Touch+ Press Dentsply; Salzburg, Osterreich] according to the manufacturer's guidelines.

24 ceramic specimens, 12 of each type of ceramic were prepared for evaluating the optical properties and roughness after applying different surface finishing (glazing and polishing) and immersing the specimen in different $\mathrm{pH}$ and different temperature solutions. Each ceramic disk

*email roxana.vasiliu@umft.ro, Phone:0745225523 
has 2 surfaces resulting 48 surfaces, 24 glazed and 24 polished. First of all the samples were cleaned ultrasonically. All the surfaces were prepared using first

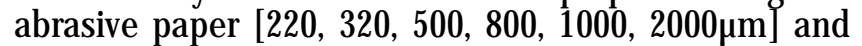
after polished with a diamond paste with $40 \mu \mathrm{m}$ particles, [Zirkopol; Feguramed, Germany] for 60 seconds each surface. After this step half of the surfaces were glazed. The glaze was applied using manufacturer's instruction's. Two layers of glaze were applied to simulate fabrication processes of the restoration.

The specimens of each material $[n=12]$ were randomly divided into three groups [ $n=4$ ] according to the immersion solution: Tea [Black Tea, Vallery] $[\mathrm{pH}=6,5]$, carbonated acidic beverages [Coca-Cola][ $p H=2,5]$, Distilled Water[D][pH=7] as the control group. The temperature were chosen to simulate the oral environment with its temperature variations.

The tea was prepared using $1 \mathrm{~g}$ of tea for $100 \mathrm{~g}$ of water. The ceramic disks were immersed in a closed individual vial containing $20 \mathrm{~mL}$ of each solution. The vials were kept in the incubator for 24 hours at temperature of $37 \mathrm{p} \mathrm{C}$ for distilled water and 55p C for tea. The vials with the carbonated acidic beverage with acid was kept for 24 hours at a $5^{\circ} \mathrm{C}$ temperature.

A digital spectrophotomer (Vita Easy Shade; Vita ZahnFabrick) was calibrated before using it with its calibration apparatus before the colour was taken. Colour measurements were performed using two backgrounds , white and black, and the spectrophotomer's tip (6-mm diameter) was placed onto the center of the specimens. The specimens were measured one time and recorded in the CIE ( Commision International de I'Eclairage) Lab colour space system.

Parameters TP (translucency), OP(opalescence) and $\mathrm{CR}$ (contrast ratio) were calculated using the formulas. The translucency parameter [TP] was calculated by the following equation:

$$
\mathrm{TP}=\left[\left(\mathrm{L}_{\mathrm{B}} *-\mathrm{L}_{\mathrm{W}} *\right)^{2}+\left(\mathrm{a}_{\mathrm{B}} *-\mathrm{b}_{\mathrm{W}} *\right)^{2}+\left(\mathrm{b}_{\mathrm{B}} *-\mathrm{b}_{\mathrm{W}}{ }^{*}\right)^{2}\right]^{1 / 2},
$$

where subscript $B$ refers to the colour coordinates against a black backing and subscript $W$ refers to those against $a$ white backing [14].

The values from $a^{*}$ and $b^{*}$ coordinates recorded (VITA Easy-shade 4 Advance, Vita Zahnfabrik, Germany) from the ceramic specimens placed on a black (B) and a white (W) backgrounds were also used to estimate the opalescence parameter (OP) according to the following formula:

$$
O P=\left[\left(a_{B}^{*}-a_{w}{ }^{2}\right)^{2}+\left(b_{B} *-b_{w}{ }^{2}\right)^{2 / 2}\right.
$$

Values of $L^{*}$ parameter were also used to calculate spectral reflectance using the following equation :

$$
Y=\left(L^{*}+16 / 116\right)^{3} X Y_{n}
$$

$Y$ values of the samples recorded on black $\left(Y_{b}\right)$ and white $\left(Y_{w}\right)$ backgrounds were used to calculate the contrast ratio (CR) parameter.

$$
\mathrm{CR}=\mathrm{Yb} / \mathrm{Yw} \text {. }
$$

CR values range from 0 that represents a transparent material and 100 a totally opaque material.

Roughness measurements were made using a profilometer [Mitotoyo SJ 201)].
The values of interest were Ra and $R z$, Ra meaning arithmetical mean roughness and $R z$ meaning the maximum roughness of the analysed surface. Five measurements were made on each side of the samples.

\section{Results and discussions}

\section{TP parameter [transluceny parameter]}

The significant changes occur after 24 hours of immersion for the feldspathic ceramic in all of the chosen immersion solutions. For the lithium disilicate ceramic the values are constantly growing after 24 hours.

After immersing the samples in tea, after 24 hours the glazed and the polished lithium disilicate samples have the same values. The feldspathic samples have much lower values, both the glazed and polished samples. After 48 hours the values for all samples from the two lines representing the two types of ceramic tend to meet and after 72 hours the lines are more similar for all the samples. There is although a remaining difference between the lithium and the feldspathic samples. The lithium samples have higher values than the feldspathic ceramic samples (fig.1).

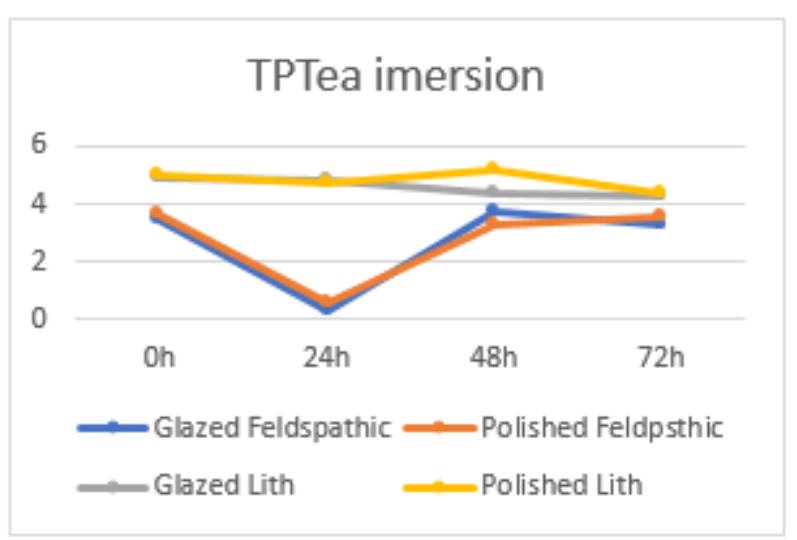

Fig. 1. TP parameter values after immersing in tea beverages

After immersing the samples in distilled water, the major differences were seen after $24 \mathrm{~h}$. The feldspathic ceramic values for TP parameter decrease comparing to the lithium disilicate. After $48 \mathrm{~h}$ the values tend to be similar and after $72 \mathrm{~h}$ the values begin to increase for the lithium disilicate glazed samples (fig. 2).

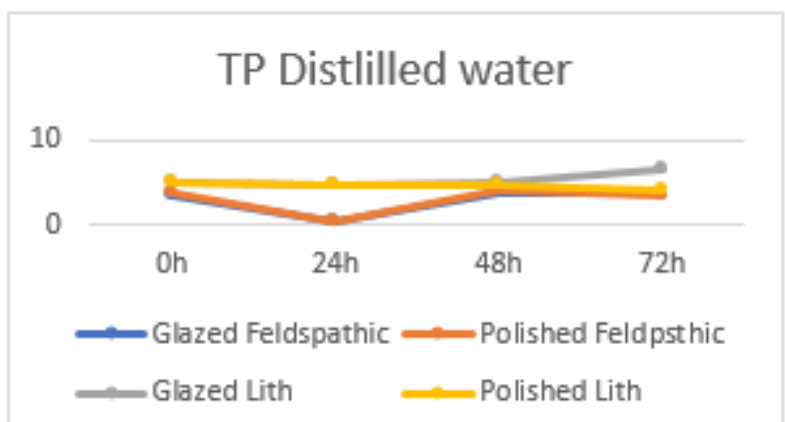

Fig. 2. TP parameter values after immersing in distilled water

After immersing the samples in carbonated acidic beverage, the values of the lithium disilicate samples begin to increase and the values for the feldspathic ceramic decrease. Even after 48 and $72 \mathrm{~h}$ after immersing the values are different between the two types of ceramic (fig.3). 


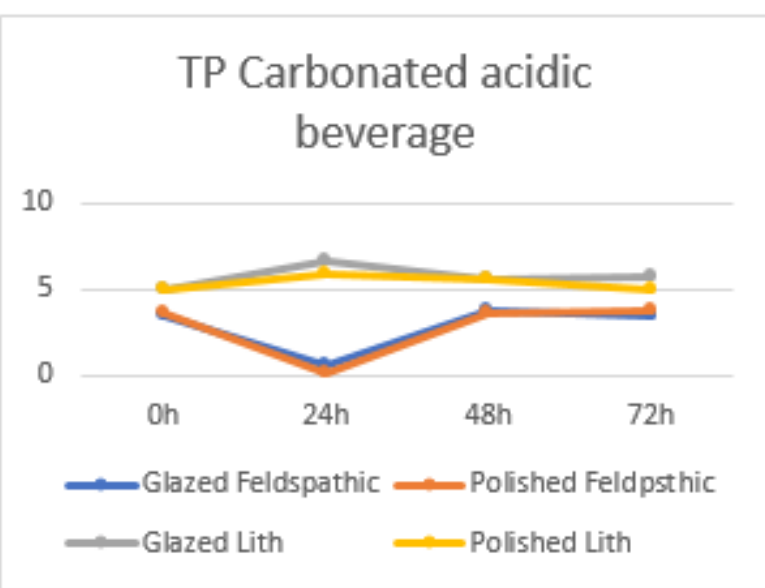

Fig. 3. TP parameter values after immersing in carbonated acidic beverages

OP parameter [opalescence parameter]

Similar to the TP parameter, the OP parameter changes significantly for the feldspathic ceramic, for both polished and glazed samples, after $24 \mathrm{~h}$ of immersion in all the solutions. For the lithium disilicate ceramic the values are constant after $24 \mathrm{~h}$ (fig.4).

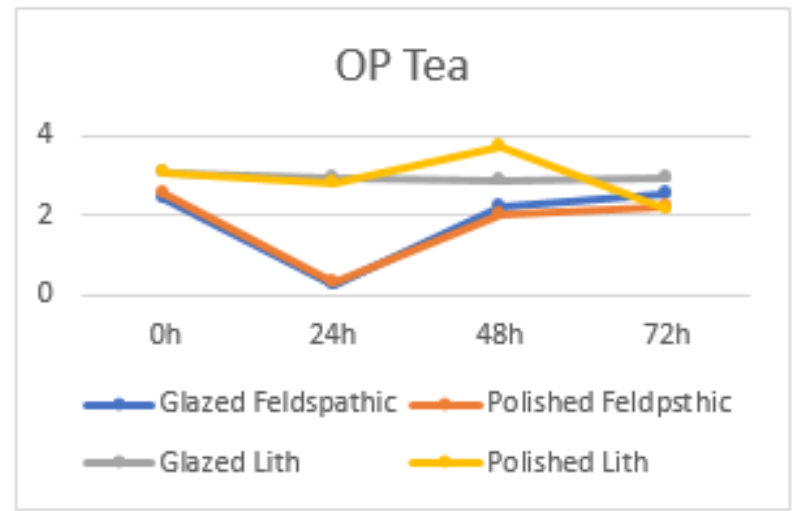

Fig. 4. OP parameter after immersing tea

After immersing the samples in tea, for lithium disilicate samples the values were constant after 24 hours and they remain constant for the glazed lithium disilicate samples for the whole time. The polished lithium disilicate samples have values that increase after $48 \mathrm{~h}$ and after $72 \mathrm{~h}$ the values decrease. For the feldspathic ceramic, the major changes occur after $24 \mathrm{~h}$ and after $48 \mathrm{~h}$ the values are increasing again, same for $72 \mathrm{~h}$. Both the glazed and the polished samples have the same path on the figure.

After $24 \mathrm{~h}$ of immersing the samples in distilled water, the values are high for the lithium disilicate ceramic and low for the feldspathic ceramic compared to non immersed samples. After 48 hours the values of both types of ceramic tend to be similar and are continuous even after $72 \mathrm{~h}$ (fig.5).

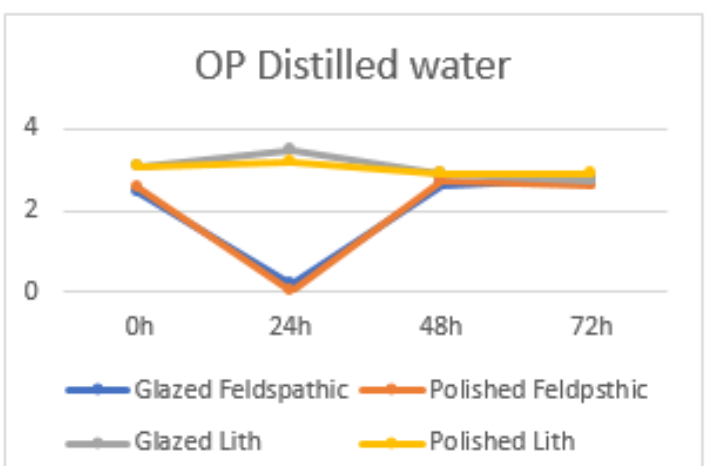

Fig. 5. OP parameter after immersing the samples in distilled water
After $24 \mathrm{~h}$ of immersing the samples in carbonated acidic beverage, the values of feldspathic ceramic are low compared to non imersed samples and the values for lithium disilicate seem to be constant. There is a difference between the glazed and polised after $24 \mathrm{~h}$ for both of the studied ceamics, the last ones have lower values for opalescence then the first ones. After $72 \mathrm{~h}$ the values for the glazed, polished feldspathic and polished lithium disilicate tend to decrease .The values for glazed lithium disilicate begin to increase after $72 \mathrm{~h}$ (fig.6).

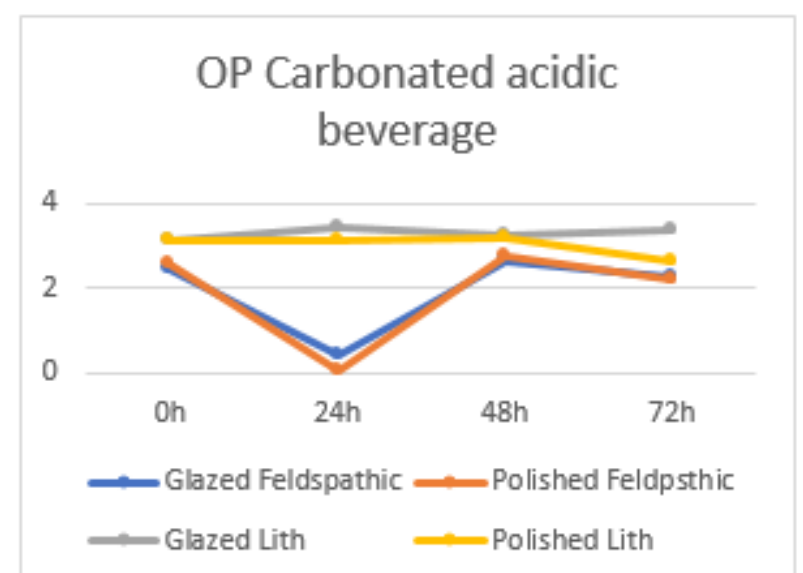

Fig. 6. OP parameter after immersing the samples in carbonated acidic beverages

CR parameter( contrast ratio parameters)

Differently from the other two studied parameters, the CR parameter in tea has the highest values for the feldspathic ceramic and especially for the glazed samples after $24 \mathrm{~h}$. After $48 \mathrm{~h}$ the polished feldspathic samples have the higher values and after $72 \mathrm{~h}$ the glazed feldspathic begins again to have high values.

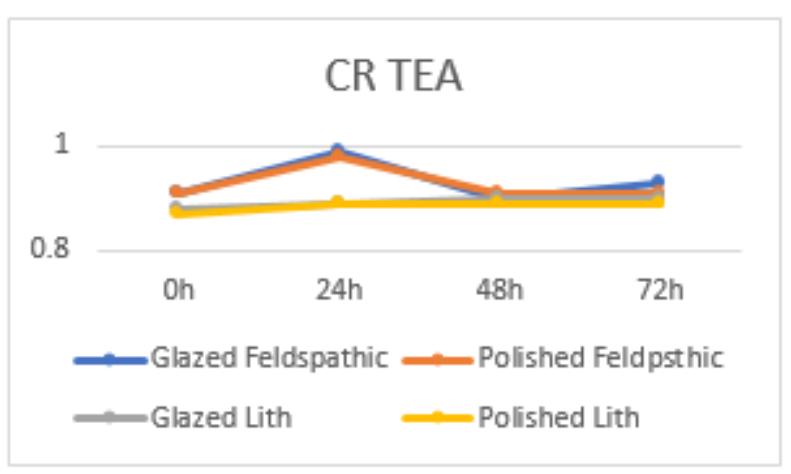

Fig. 7. The CR parameter values after immersing in tea

For the lithium disilicate ceramic, the CR parameter remains high for the glazed samples after $24 \mathrm{~h}$. After 48 and $72 \mathrm{~h}$ the values of both glazed and polished samples continue to increase.

In distilled water, both the glazed and polished feldspathic samples have the same values in chosen time 24,48 and $72 \mathrm{~h}$. There is a difference for the lithium disilicate samples, the glazed samples prove to have a higher CR parameter after 24- $48 \mathrm{~h}$ and after 72 the values decrease compared to the polished lithium disilicate samples.

In carbonated acidic beverage, after $24 \mathrm{~h}$ the glazed and polished feldspathic samples have higher values than the lithium polished and glazed samples. After $48-72 \mathrm{~h}$ the values seem to be the same and continuous. 


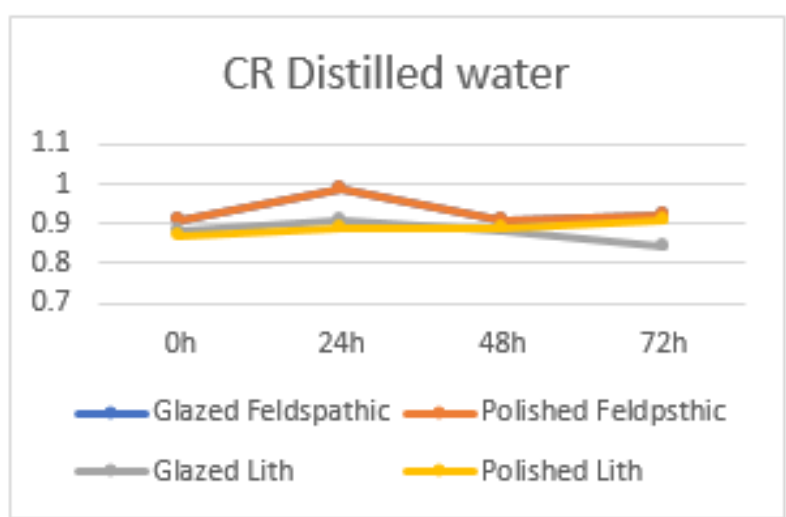

Fig. 8. CR parameter values after immersing in distilled water

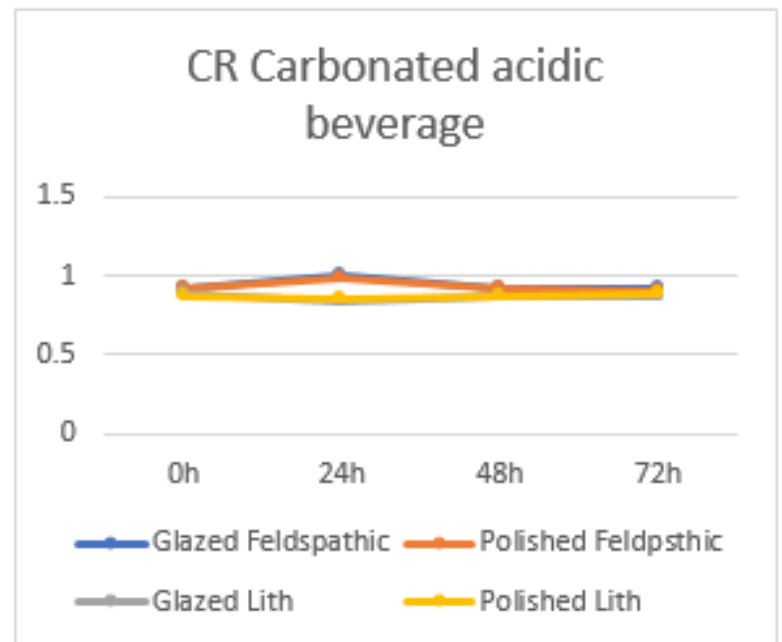

Fig. 9. CR parameter values after immersing the samples in carbonated acidic beverages

\section{Ra parameter}

The higher Ra values after the immersion of the probes in tea after $24 \mathrm{~h}$ is for the polished feldspathic samples. After $48 \mathrm{~h}$ the higher roughness is the glazed feldspathic and after $72 \mathrm{~h}$ the values for both polished feldspathic and

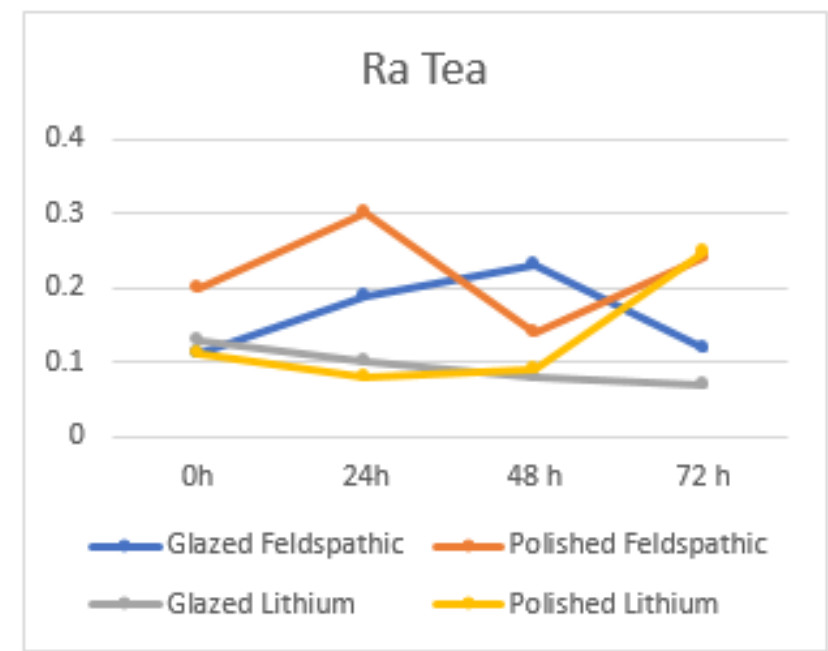

Fig. 10. Ra parameter for the tested samples

lithium are high. The lowest roughness after 24,48 and 72 $\mathrm{h}$ is for the glazed lithium disilicate samples (fig. 10).

The polished feldspathic ceramic samples prove to have the highest Ra values and the values maintain high for 48 and 72 hours after immersing them in distilled water. The

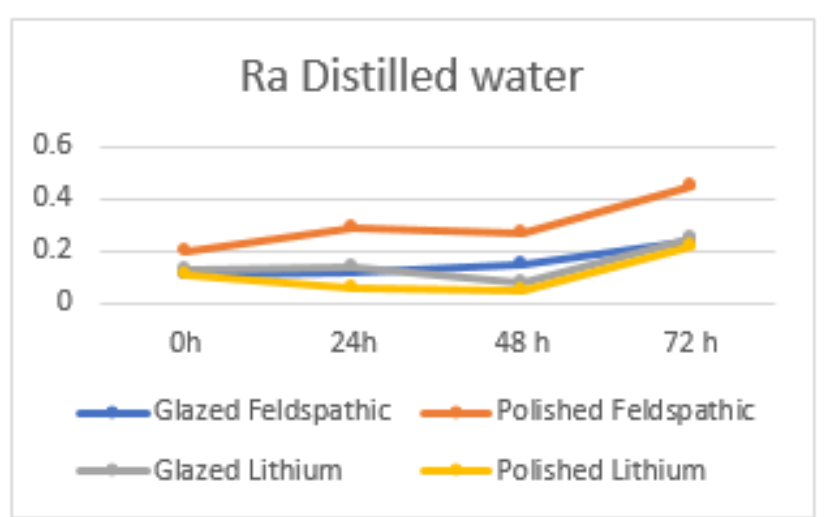

Fig. 11. Ra values for the tested samples

lowest values belong to the polished lithium ceramic for the chosen time (fig.11).

After immersing the samples in carbonated acidic beverages, the highest Ra parameter belongs to the

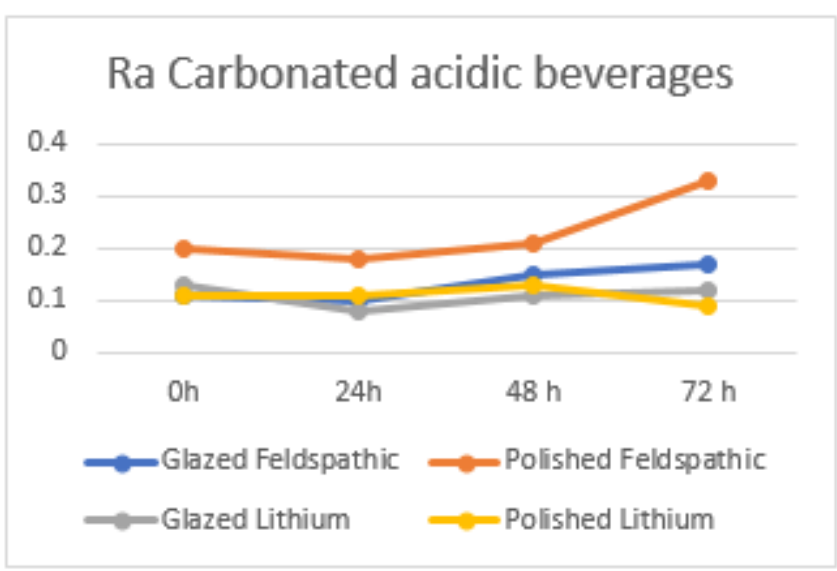

Fig. 12. Ra values for the tested samples immersed in carbonated acidic beverages

polished feldspathic ceramic. The lowest Ra values are for the lithium polished samples (fig.12).

$R z$ parameter

Rz parameter represents the highest roughness of the material. The $\mathrm{Rz}$ values after immersing the samples in tea proved that the polished feldspathic ceramic has the highest values after 24 and $72 \mathrm{~h}$. The glazed feldspathic has lower values after 24 and $72 \mathrm{~h}$ but higher after 48 hours than the polished samples. The polished lithium disilicate samples have lower values than the glazed samples after

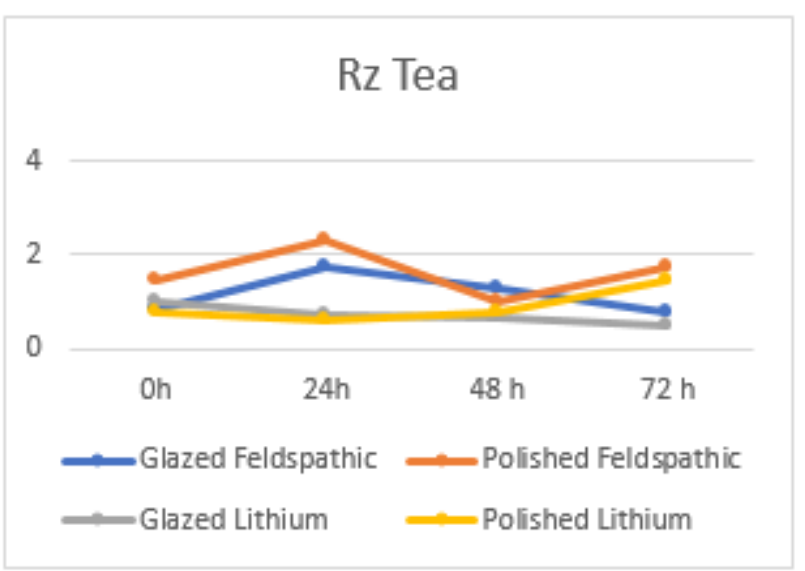

Fig. 13. Rz parameter values 
$24 \mathrm{~h}$. After $48 \mathrm{~h}$ the glazed samples have lower values (fig.13).

After immersing the samples in distilled water, the differences that occur are for the glazed lithium disilicate samples. The values are higher than the polished samples

\section{Rz Distilled water}

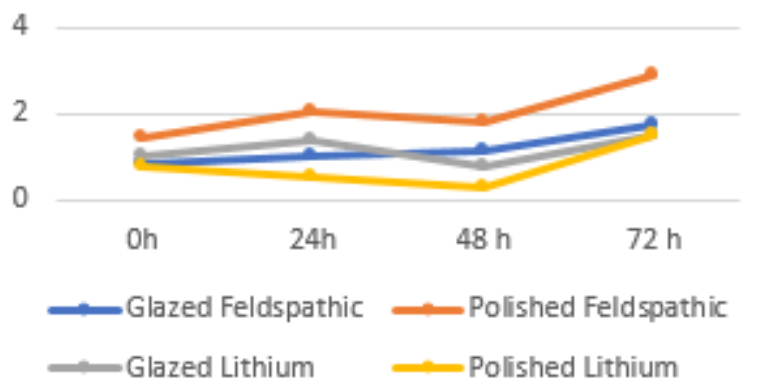

Fig. 14. Rz parameter values

after $24 \mathrm{~h}$. The lower values for Rz parameter are for the polished lithium samples (fig.14).

After immersing the probes in distilled water for the chosen time the Rz values were higher for the polished feldspathic ceramic and lower for the polished lithium disilicate ceramic. The differences between the two ceramic according to the surface finishing were keptduring all the time.

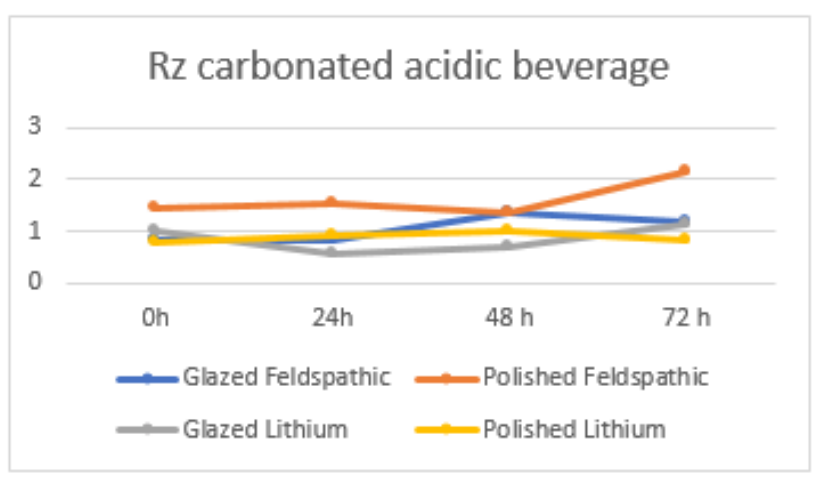

Fig. 15. Rz parameter values

In carbonated acidic beverages the polished feldspathic $R z$ values were high and the lower values of $R z$ belong to the glazed lithium disilicate ceramic (fig. 15).

The results of this study showed that the immersion has some influence on the optical and roughness of the two types of ceramics, but the major influence is made by the surface finishing and the type of ceramic. The presentstudy simulated the clinical situation in which the lithium disilicate ceramic and feldspathic ceramic are immersed in tea, distilled water and carbonated acidic beverages for 72 hours which represents 4 years of clinical use. Ceramic materials have intrinsically multiple flows after obtaining them because of the distribution of crystals in the glassy matrix and and sealing these floes with polishing and glazing should improve the surface of the ceramic[15].

Some authors found that the initial smoothness of the glazed surface of ceramic to be superior to the polished surface $[16,17]$ and some authors considered that the polished surface could equal the glazed surfaces. The results of this study concluded that it depends on the type of the ceramic. The polished surface of the lithium disilicate ceramic was smoother than the glazed and for the feldspathic was the contrary.

The optical properties such as TP, OP and CR were influenced by the immersion in the solutions. In all solutions after $24 \mathrm{~h}$ there were visible changes for both ceramics, but the feldspathic ceramic proved to be more influenced. The TP and OP parameters were higher for the lithium disilicate ceramic, meaning that is has higher translucency and opalescence that are needed for aesthetic effect. The CR parameter was high for the feldspathic ceramic proving that the feldspathic ceramic is more opaque than the other one and that influences the aesthetics.

The translucency parameter [TP] is a standardized method to calculate translucency considering the entire visible spectrum [18]. For materials commonly viewed in reflection, the TP can be established as the colour difference between a specified thickness of material on black and white backings. The microstructure of the ceramic, mainly the average particle size, may explain the differences in TP values [19].

Previous studies $[20,21]$ concluded that it is a strong correlation between that TP and CR parameters as TP decreases, CR increases. The feldspathic ceramic has an decreased TP parameter and a higher CR value. Especially the CR parameter was higher for the feldspathic probes immersed in tea and carbonated acidic beverage. CR measures diffuse reflectance, does not detect small changes in light transmission, when materials presenthigh scattering and absorption coefficients [22].

\section{Conclusions}

Within the limitations of this study, results suggested that the major difference when it comes to optical properties depends only on the type of ceramic.

Roughness with Ra and Rz parameter showed that the parameters were influenced by the surface finishing of both type of ceramics. The feldspathic polished ceramic proved to be more rough than the glazed feldspathic ceramic. The feldspathic ceramic has indication only for glazing. There were little differences between the polished and glazed lithium disilicate ceramic. The lithium disilicate ceramic has indication for glazing and polishing. The lithium disilicate ceramic proved to have better optical properties when the optical parameters of the ceramics were compared.

The $\mathrm{pH}$ and temperature changes showed little effect on the optical properties and roughness of the ceramics.

\section{References}

1. MAYEKAR S, Shades of a color. Illusion or reality? Dental Clinical North Am, 2001;p 45:155-72.

2. SALESCKI C. Colour, light, and shade matching. J ournal of Prosthetic Dentistry 1972;27:263-8.

3. DOZIC A, KLEVERLAAN C, ZOHAIRY A, FEILZER AJ. KHASHAVAR G. Performance of five commercially available tooth colour- measuring devices. J ournal of Prosthodontics 2007;16:93-100.

4. GOODKING RJ, SCHABACHER WB. Use of fiber- optic colorimeter for an in vivo colour measurements.J ournal of Prosthetic Dentistry 1987; 58(5):535-42.

5. JOINER A. Tooth colour: a review of the literature. Journal of Dentistry 2004;32:3-12.

6. DAGG H, O' CONELL B, C. Influence of some different factors on the accuracy of shade selection. Journal of Oral Rehabilitation 2004;31:900-4.

7.CHANG J , SAKAI M, KRISTIANSEN J, ISHIKAWA-NAGAI S. The optical effect of composite luting cement on all ceramic crowns. Journal of Dentistry 2009;37;937-943. 
8. DOZIC A, TSAGKARI M, M. Color management of porcelain veneer: influence of dentin and resin cements colours. Quintessence Int 2010;41:567-573.

9.NAKAMURA T, SAITO O, FUYIKAWA J ,. Influence of hear pressed ceramic crowns. Journal of Oral Rehabilitation 2002;29:805-809.

10. FRANKENBERGER $R$, TASHNER $M$. Leucite- reinforced glass ceramic inlays and onlays after 12 years. Journal of Adhensive Dentistry 2008;10:393-8.

11.0TTO T SSHNEIDER D. Long term clinical results of chairside Cerec CAD/CAM inlays and onlays :a case series. International J ournal of Prosthodontics 2008;21:53-9.

12.DIENG FY, CLARK AE, NEAL D. Surface degradation of dental ceramics as a function of environment $\mathrm{pH}$. J ournal of Dental Research 2013;92:467-71.

13. PALMER DS, BARCO T, BILLY EJ. Temperature extremes produced orally by hot and cold liquids. Journal of Prosthetic Denistryt 1992;67:325-7.

14.POROJAN, L., SAVENCU, C., POROJAN, S., Applications of Heatpressed Ceramics for Single Tooth Restorations. Rev. Chim. (Bucharest), 67, no.1,2016, p 123.
15. POROJAN, S., POROJAN, L., Evaluation of Co-Cr Dental Alloys Welds Corrosion. Rev. Chim. (Bucharest), 66, no.3, 2015, p 357.

16. MANJURAN N, SRELAL T.An in vitro study to identify a ceramic polishing protocol effecting smoothness superior to glazed surface. Journal Indian Prosthodontics Soc. 2014 Sep;14(3):219-27.

17. SAVENCU, C., POROJ AN, S., POROJAN, L., Analysis of Internal and Marginal fit of Metal-ceramic Crowns During Processing, Using Conventional and Digitized Technologies. Rev Chim. (Bucharest), 69, no. 7, 2018, p 1699.

18. ALVARO DELLA B. Optical properties of CAD-CAM ceramic systems. J ournal of Dentistry Volume 42, Issue 9, September 2014, p1202-1209 19.0' NEIL S, LEINFELDER KF.Effect of metal surfacing on the colour characteristics of porcelain veneer. Dent Mater 1987;3-97-101.

20.NIUE. AGUSTIN M, DOUGLAS R. Colour match of machinable lithium disilicate ceramics. Effects of cement colour and thickness. Journal of Prosthetic Dentistry 2014;111.42-50.

21. TURGOT S, BAGIS B. Colour stability of laminate veneers an in vitro study. J ournal of Dentistry 2011;39( Suppl 3)e57-64.

22. CHU S), TRUSHKOWLY R. Dental colour matching instrument and systems, review of clinical and research aspects. J ournal of Dentistry 2010;38(Suppl2)e2-16.

Manuscript received: 19.12 .2018 